\title{
Goal-Framing and Temporal-Framing: Effects on the Acceptance of Childhood Simple Obesity Prevention Messages among Preschool Children's Caregivers in China
}

\author{
Qingmao Rao ${ }^{1}$, Li Bai ${ }^{1}$, Yalan LV ${ }^{1}$, Abu Saleh Abdullah ${ }^{2,3,4}{ }^{\oplus}$, Ian Brooks ${ }^{5,6}$, Yunjie Xie ${ }^{7}$, \\ Yong Zhao ${ }^{8, *(1)}$ and Xiaorong Hou ${ }^{1, *(1)}$ \\ 1 College of Medical Informatics, Chongqing Medical University, Chongqing 400016, China; \\ rqm@stu.cqmu.edu.cn (Q.R.); 2017111298@stu.cqmu.edu.cn (L.B.); yalanlv@126.com (Y.L.) \\ 2 Global Health Research Center, Duke Kunshan University, Kunshan 215347, China; \\ abu.abdullah@dukekunshan.edu.cn \\ 3 Duke Global Health Institute, Duke University, Durham, NC 27710, USA \\ 4 Boston University School of Medicine, Boston Medical Center, Boston, MA 02118, USA \\ 5 Center for Health Informatics, University of Illinois, Champaign, IL 61820, USA; ianb@illinois.edu \\ 6 School of Information Sciences, University of Illinois, Champaign, IL 61820, USA \\ 7 College of Preschool Education, Chongqing University of Education, Chongqing 400067, China; \\ xieyj@cque.edu.cn \\ 8 School of Public Health and Management, Chongqing Medical University, Chongqing 400016, China \\ * Correspondence: zhaoyong@cqmu.edu.cn (Y.Z.); xiaoronghou@cqmu.edu.cn (X.H.); \\ Tel.: +86-138-8346-0842 (Y.Z.); +86-138-8390-1680 (X.H.)
}

Received: 6 December 2019; Accepted: 22 January 2020; Published: 26 January 2020

\begin{abstract}
A range of intervention models are available for childhood obesity prevention; however, few studies have examined the effectiveness of intervention messages. This study developed childhood simple obesity prevention messages on the basis of goal-framing and temporal-framing effects to improve message acceptance among the caregivers of preschool children and explored associated factors. A cross-sectional study was conducted among 592 caregivers of preschool children in urban kindergartens in China during March to April 2019. The framing messages were developed based on prospect theory and construal level theory. The majority (48.4\%) of caregivers found the gain-framed, present-oriented message most salient for acceptance. We found that gender, education background, theme, and the use of negative words have impacts on goal-framing effects; and previous participation in a health related intervention, career category, and the theme have impacts on temporal-framing effects $(p<0.001)$. Goal-framing effects and temporal-framing effects can influence each other $(p<0.001)$. The findings suggest that the gain-framed, present-oriented message could be considered a strategy to improve the acceptance of information by caregivers. When framing a message, subtle differences like using negative words might affect the exertion of framing effects.
\end{abstract}

Keywords: goal-framing effects; temporal-framing effects; acceptance; health message; caregivers

\section{Introduction}

Simple obesity is caused by excessive accumulation of fat as the body absorbs more calories than it consumes [1]. Childhood simple obesity was once considered a problem only in high-income countries, but is now dramatically on the rise in low and middle-income countries, particularly in urban settings [2]. According to the data provided by the International Obesity Task Force and the World Health Organization disease burden report, the rate of global childhood simple obesity is 
currently $2 \%-3 \%$, and the overall trend is on the rise in all regions [3,4]. Geserick et al. [5] found that the preschool years are a critical period for childhood simple obesity, and the rapid increase in body mass index (BMI) among children aged 2 to 6 years old was highly correlated with obesity in adolescence and even adulthood, with a relative risk of 1.43. Simple obesity among preschool children can be regarded as a major factor for several chronic diseases, such as hypertension, dyslipidemia, and diabetes $[6,7]$. Therefore, it is necessary to prevent simple obesity among children and intervene at the preschool stage (3-6 years of age [8]).

Childhood simple obesity is also a typical lifestyle disease [9]. Unhealthy diets such as excessive amounts of sweets and unhealthy behavior, e.g., picking food to eat, as well as a sedentary lifestyle, may lead to the development of preschool childhood obesity $[10,11]$. Especially under the influence of traditional Chinese family culture, the caregivers often reward their children with snacks, such as candy, and encourage them to eat more food; this phenomenon is common in the skip-generation raising families [12]. Parents, grandparents, and other caregivers prepare the food of preschool children. Many Chinese scholars have conducted several studies in various regions of China and found that increasing the level of health knowledge of the caregivers can encourage children to have a positive attitude toward health and to maintain a healthy lifestyle; thus, the prevention and control of preschool children's simple obesity can be improved [13-15]. This scenario underscores the need for family intervention in preventing childhood simple obesity.

Caregivers' acceptance of health promotion messages is limited [16,17]. The difference between a health message and the general message is that the former is a normative, objective, and rigorously written medical material. Caregivers with different cognitive abilities and from different professional education levels may have considerable differences in the degree of and the time they need for acceptance [18]. At present, health message acceptance can be improved by changing the presentation form of materials, such as by using appropriate pictures, simple grammar and vocabulary, and concise presentation [19-21]. The current study aimed to explore the acceptance effects of four commonly used health communication message formats (i.e., gain-framed, loss-framed, present-oriented, and future-oriented).

The "framing effect" was first proposed by Tversky and Kahneman in 1981 [22]. Several studies have shown that message framing is a reliable way to improve the messaging utility, and adopting an appropriate frame for a message on a particular theme can enhance the acceptance of this message by the target population [23-25]. Myers [26] thinks that the health framing effect plays an important role in promoting healthy behavior.

In framing effects, the goal-framing and temporal-framing effects are especially emphasized. Goal-framing effects based on prospect theory suggest that factually equivalent messages have different levels of persuasiveness depending on how these messages are framed. A gain-framed message focuses on the positive consequences of performing an action, whereas a loss-framed message focuses on the negative consequences of inaction [27]. Rothman [28] and most scholars argued that a gain-framed message is acceptable for disease prevention, whereas a loss-framed message is compelling for disease detection. However, some scholars had drawn opposite conclusions [29]. Temporal-framing effects are based on construal level theory, which proposes that people use abstract mental representations to perceive events in the distant future but not in the near future [30]. A message can be classified into present-oriented and future-oriented frames depending on the time perspective. The present-oriented framing effect was stronger than the future-oriented one, as determined by many researchers [31-33].

Therefore, it is necessary to prevent and intervene in simple obesity and intervention among children during the preschool stage on the basis of goal and temporal-framing effects. This research explored whether the acceptance of prevention messages regarding simple obesity in preschool-aged children can be increased by gain-framed messages and present-oriented messages among caregivers, and demonstrated the roles of demographic characteristics, themes of healthy behavior, personal involvement, and use of negative words within the message acceptance of moderating framing effects. 


\section{Materials and Methods}

\subsection{Study Design}

A cross-sectional study about the caregivers' acceptance of the different framings of prevention messages regarding simple obesity in preschool-aged children was conducted in urban kindergartens in China from March to April 2019. We adopted convenience sampling to select eight urban kindergartens, which were located in Chongqing, China. A self-administered paper questionnaire and a self-filling online questionnaire were used. We also explored whether gender, education background, theme, the use of negative words, previous participation in a health related intervention, and career category might affect the recipients' acceptance of framing messages.

\subsection{Participant Selection}

The following were the inclusion criteria. The participants must be actual caregivers of preschool children, who are defined as the people responsible for the diets and exercise levels of preschool children who assume the duty of guardianship of those preschool children.

We recruited 312 participants through an online survey. Eight kindergarten teachers supported data collection. These teachers were responsible for posting an online link to the questionnaire, a message containing the survey purpose and process, and instructions for filling in the questionnaire in the WeChat group of preschool children's caregivers. WeChat is a free application that provides instant messaging services for smart terminals. Caregivers who were interested in this survey could click on the link and fill in the questionnaire.

We recruited 280 participants through an offline (face-to-face) survey. We sent three trained investigators to the kindergartens for data collection.

\subsection{Questionnaire}

We referred to the review articles [24,34] and research papers [35-37] of framing effects to determine the questionnaire content of demographic characteristics. The contents of the prevention messages regarding simple obesity in preschool children were derived from clinical research [38,39], epidemiological studies [40], and clinical practice guidelines [41-43]. We processed these prevention messages into health-framed messages according to the prospect theory and construal level theory (Appendix A). The content of the questionnaire was finalized after several discussions by an expert group. In March 2019, the pre-survey investigated 31 caregivers to test the reliability of the questionnaire. The Cronbach's alpha of the questionnaire (demographic characteristics and framing messages) was found to be 0.817 . The Cronbach's alpha for the framing messages materials was 0.893 .

Questions included caregiver's relationship with the children, gender, age, ethnicity, educational background, type of work, whether or not health interventions for childhood obesity had been before, the monthly cost on the child's diet, and multiple questions on message framing. Participants observed four different types of framing message on the same theme at the same time. They were asked to read the messages carefully and chose the most acceptable one (Appendix B).

The design process of the framing message was as follows. We first identified four prevention themes for obesity among preschool children: dietary habits (Dh), dietary behavior (Db), physical activities $(\mathrm{Pa})$, and sleep factors (Sf). Then, we designed four sets of framing messages in four themes: a gain-framed, present-oriented message (GP message); a gain-framed, future-oriented message (GF message); a loss-framed, present-oriented message (LP message); and a loss-framed, future-oriented message (LF message) (Figure 1). 


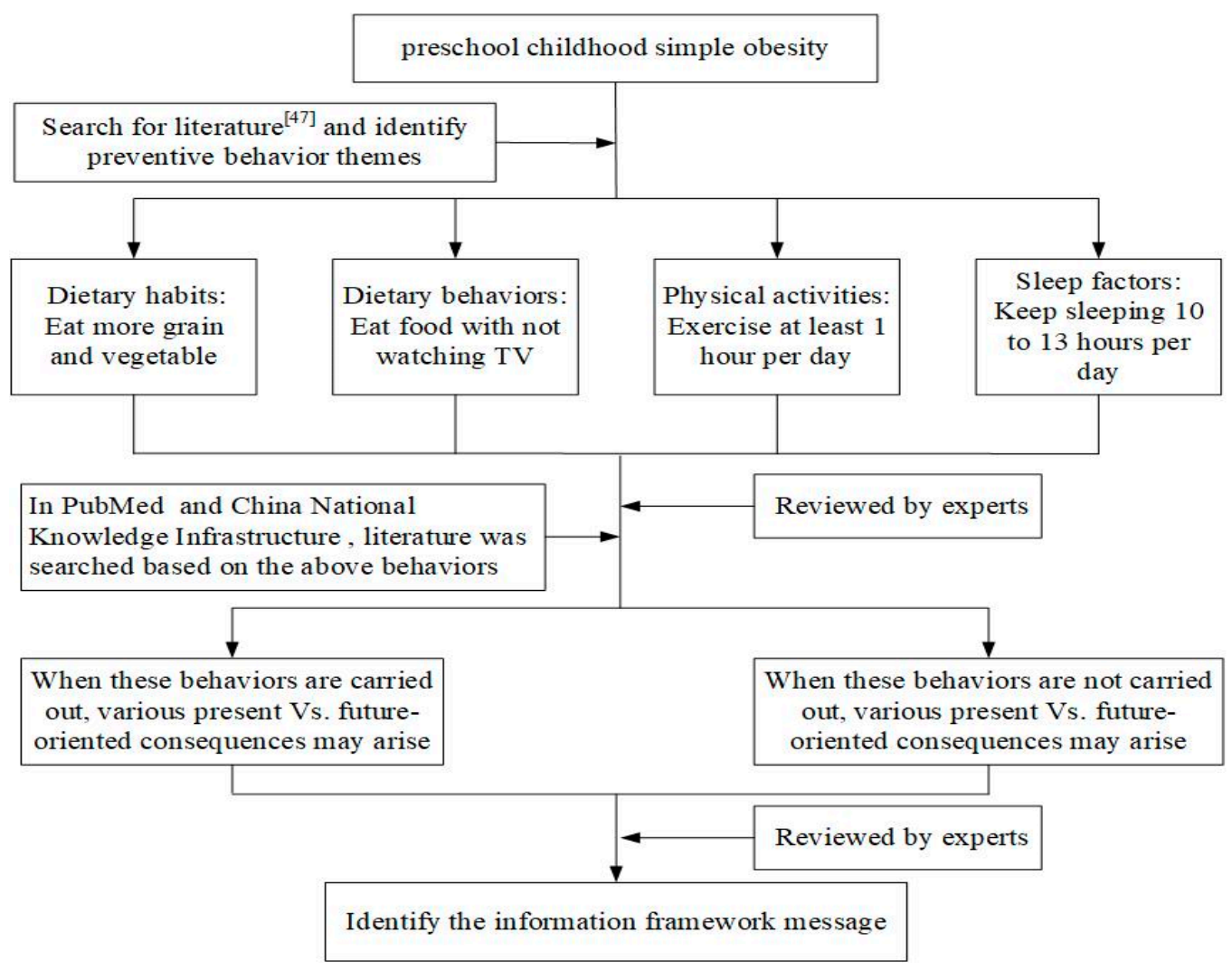

Figure 1. The framing messages' design process.

\subsection{Data Collection}

Demographic questions were answered by the participants. Meanwhile, we allowed the participants to choose the framed message that most agreeable among the four. The answer to the online questionnaire was recorded automatically on the client-side. The answers to the offline questionnaire were provided by participants and were imported into an Excel file by the interviewers.

\subsection{Ethical Aspects}

The study was approved by the ethics committee of Chongqing Medical University (approval number: 2018011). The participants provided informed consent for inclusion before joining this study.

\subsection{Statistical Analysis}

Data were processed by Excel software before entry into the database. Data analyses were performed using SPSS 20.0 software (IBM Corporation, Armonk, NY, US). For the demographic characteristics of caregivers, frequencies and percentages were calculated for categorical variables and means and standard deviations for continuous variables. Percentages were used to describe caregivers' choices in framing messages. Pearson's chi-square test and the Bonferroni method were used to analyze the differences in caregivers' choice tendencies of framing messages among the four different themes. Statistical analyses were conducted using a two-sided test. Binary logistic regression analysis was implemented to analyze the factors associated with framing effects. A $p$-value not more than 0.05 was considered statistically significant.

\subsection{Quality Control}

The offline research team members, including three students (two postgraduate and one undergraduate), received standardized investigation training. Investigators were to understand the purpose and methodology of the study in detail and have extensive experience in dealing with 
potentially sensitive issues. In online research, the quality of the questionnaire answers can be guaranteed through screening of answer results and answering time.

\section{Results}

A total of 592 subjects participated in the survey. After excluding the invalid questionnaires (87), 505 sets of data from caregivers were available for analyses with a valid participation rate of $85.3 \%$.

\subsection{Demographic Characteristics of the Caregivers}

The demographic characteristics of the samples are presented in Table 1. The majority of caregivers were the mothers of children. The caregivers' mean age was 39.1 years old (11.07 SD). The Han ethnicity constituted $96.0 \%$ of the sample. This survey was basically carried out in urban kindergartens, so $258(51.1 \%)$ of the caregivers had a university or three -year college education. The job categories of the caregivers in decreasing order were as follows: 166 administrative workers, soldiers, teachers, medical staff members, and scientists (32.9\%); 124 workers in commerce (24.6\%); 91 workers $(18.0 \%) ; 69$ unemployed (13.7\%); and 18 farmers (3.6\%). Among the caregivers, $260(51.5 \%)$ allot between 500 and $1000 \mathrm{CNY}$ for their children's monthly dietary expenses. More than half $(75.2 \%)$ of the caregivers did not previously participate in any health interventions for preschool childhood obesity voluntarily; an example would be receiving relevant health education. We compared the demographic characteristics of online and offline groups and found that the career category of the online group was dominated by administrative organs, soldiers, teachers, medical staff, scientists, and commerce workers, while the career category of the offline group was dominated by workers and commerce workers. In the online group, the number of caregivers who were grandparents was a little lower than that of the offline group, and the number of caregivers who were female, of high educational background, and paid high expenses for their children's diets, was higher than that of the offline group.

Table 1. Demographic characteristics of caregivers by source $(n=505)$.

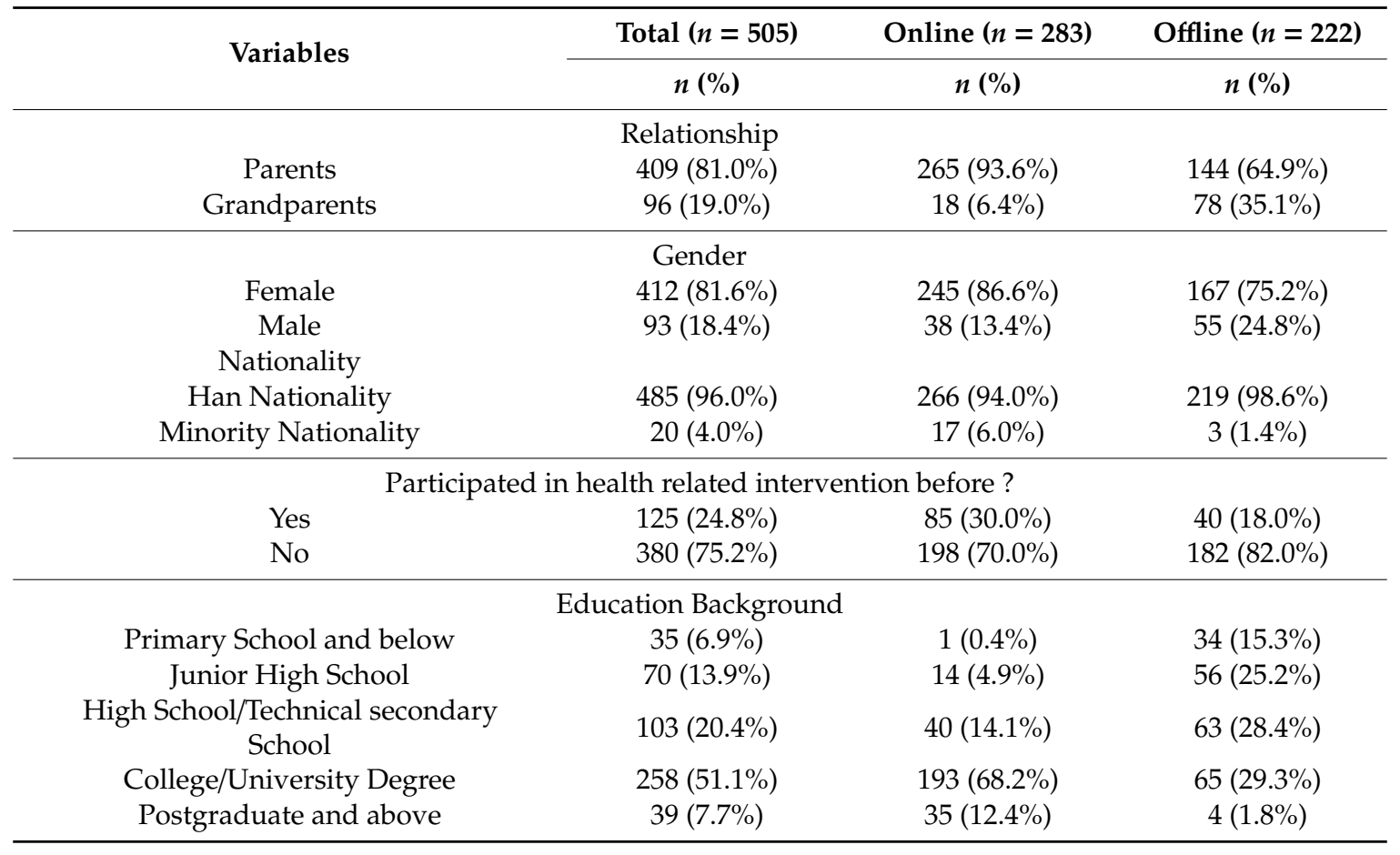


Table 1. Cont.

\begin{tabular}{|c|c|c|c|}
\hline \multirow{2}{*}{ Variables } & Total $(n=505)$ & Online $(n=283)$ & Offline $(n=222)$ \\
\hline & $n(\%)$ & $n(\%)$ & $n(\%)$ \\
\hline \multicolumn{4}{|c|}{ Career Category } \\
\hline $\begin{array}{l}\text { Administrative Organs, Soldiers, } \\
\text { Teacher, Medical Staff, Scientist }\end{array}$ & $166(32.9 \%)$ & $133(47.0 \%)$ & $33(14.9 \%)$ \\
\hline farmer & $18(3.6 \%)$ & $5(1.8 \%)$ & $13(5.8 \%)$ \\
\hline Worker & $91(18.0 \%)$ & $21(7.4 \%)$ & $70(31.6 \%)$ \\
\hline Commerce & $124(24.5 \%)$ & $81(28.6 \%)$ & $43(19.3 \%)$ \\
\hline Retire & $37(7.3 \%)$ & $15(5.3 \%)$ & $22(9.9 \%)$ \\
\hline Unemployed & $69(13.7 \%)$ & $28(9.9 \%)$ & $41(18.5 \%)$ \\
\hline \multicolumn{4}{|c|}{ Monthly children's dietary expenses ( 1 USD $\approx 7 \mathrm{RMB})$} \\
\hline$<¥ 500$ & $103(20.4 \%)$ & $44(15.5 \%)$ & $59(26.6 \%)$ \\
\hline$¥ 500-¥ 1000$ & $260(51.5 \%)$ & $148(52.3 \%)$ & $112(50.4 \%)$ \\
\hline$¥ 1001-¥ 1500$ & $94(18.6 \%)$ & $60(21.2 \%)$ & $34(15.3 \%)$ \\
\hline$>¥ 1500$ & $48(9.5 \%)$ & $31(11.0 \%)$ & $17(7.7 \%)$ \\
\hline
\end{tabular}

\subsection{Caregivers' Choices of Framing Messages}

The caregivers' acceptance of framing messages is shown in Table 2. The majority of the caregivers found that the GP message was highly salient for acceptance in terms of dietary habits, physical activities, and sleep factors. However, more than half (50.1\%) of the caregivers found the LP message most acceptable in terms of dietary behavior.

Table 2. Caregivers' choices of framing messages $(n=505)$.

\begin{tabular}{ccccc}
\hline \multirow{2}{*}{ Theme } & \multicolumn{4}{c}{ Framing Type } \\
\cline { 2 - 5 } & GP Message & GF Message & LP Message & LF Message \\
\hline Dietary Habits & $385(76.2 \%)$ & $43(8.5 \%)$ & $63(12.5 \%)$ & $14(2.8 \%)$ \\
Dietary Behaviors & $182(35.8 \%)$ & $11(2.4 \%)$ & $253(50.1 \%)$ & $59(11.7 \%)$ \\
Physical Activities & $304(60.2 \%)$ & $125(24.8 \%)$ & $38(7.5 \%)$ & $38(7.5 \%)$ \\
Sleep Factors & $276(54.7 \%)$ & $177(35.0 \%)$ & $30(5.9 \%)$ & $22(4.4 \%)$ \\
\hline
\end{tabular}

We analyzed the two groups of framing messages separately to better analyze the effects of the goal-framing and temporal-framing effects. As shown in Table 3, in the goal frame message, a significant difference was found in the dietary behavior theme ("b) and other themes ("a") $(p<0.05)$. In the temporally-framed message, a significant difference was observed in the dietary habits (dietary behaviors) theme ("a") and the physical activity (sleep factors) theme (" $b$ ") $(p<0.05)$.

\subsection{Binary Logistic Regression Analyses for the Factors Influencing the Framing Effects}

To further investigate the factors that affect the acceptance of framing messages, the study performed binary logistic regression analysis. According to the results of Table 3 and previous studies, we chose twelve parameters as independent variables. The two logistic models were statistically significant. $\left(\chi^{2}=558.353, p<0.001 ; \chi^{2}=224.482, p<0.001\right)$.

As shown in Table 4, in the goal framing model, gender, education background, theme, the use of negative words, and temporal framing were statistically significant $(p<0.05)$. Compared with the Dh theme, caregivers were more willing to accept the gain-framed message in Sf theme. The combination of the message and the present-oriented frame made caregivers more willing to accept the gain-framed message. Being female, having a lower educational background, the Db theme, and the existence of negative words in a message made caregivers more willing to accept the loss-framed message respectively. 
Table 3. Chi-square test and pair-wise comparison of the results.

\begin{tabular}{|c|c|c|c|c|c|}
\hline \multicolumn{6}{|c|}{ Goal Framing Effects } \\
\hline Variables & $\begin{array}{c}\text { Gain-Framed Message } \\
n(\%)\end{array}$ & $\begin{array}{c}\text { Loss-Framed Message } \\
n(\%)\end{array}$ & $\begin{array}{l}\text { Total } \\
n(\%)\end{array}$ & $x^{2}$ & $p$ \\
\hline $\begin{array}{l}\text { Dietary Habits } \\
\text { (Dh) }\end{array}$ & $\begin{array}{l}428 \mathrm{a} \\
(84.8)\end{array}$ & $\begin{array}{c}77 \mathrm{a} \\
(15.2)\end{array}$ & $505(100.0)$ & 467.203 & $0.000^{* *}$ \\
\hline $\begin{array}{l}\text { Dietary Behaviors } \\
(\mathrm{Db})\end{array}$ & $\begin{array}{l}193 b \\
(38.2)\end{array}$ & $\begin{array}{l}312 \mathrm{~b} \\
(61.8)\end{array}$ & $505(100.0)$ & & \\
\hline $\begin{array}{l}\text { Physical Activities } \\
\text { (Pa) }\end{array}$ & $\begin{array}{l}429 \mathrm{a} \\
(85.0)\end{array}$ & $\begin{array}{l}76 \mathrm{a} \\
(15.0)\end{array}$ & $505(100.0)$ & & \\
\hline $\begin{array}{l}\text { Sleep Factors } \\
(\mathrm{Sf})\end{array}$ & $\begin{array}{l}453 \mathrm{a} \\
(89.7)\end{array}$ & $\begin{array}{c}52 \mathrm{a} \\
(10.3)\end{array}$ & $505(100.0)$ & & \\
\hline \multicolumn{6}{|c|}{ Temporal framing effects } \\
\hline Variables & Present-oriented message & Future-oriented message & $\begin{array}{l}\text { Total } \\
n(\%)\end{array}$ & $x^{2}$ & $p$ \\
\hline $\begin{array}{l}\text { Dietary Habits } \\
\text { (Dh) }\end{array}$ & $\begin{array}{l}448 \mathrm{a} \\
(88.7)\end{array}$ & $\begin{array}{c}57 \mathrm{a} \\
(11.3)\end{array}$ & $505(100.0)$ & 155.575 & $0.000 * *$ \\
\hline $\begin{array}{l}\text { Dietary Behaviors } \\
(\mathrm{Db})\end{array}$ & $\begin{array}{l}434 \mathrm{a} \\
(85.9)\end{array}$ & $\begin{array}{l}71 \mathrm{a} \\
(14.1)\end{array}$ & $505(100.0)$ & & \\
\hline $\begin{array}{l}\text { Physical Activities } \\
\text { (Pa) }\end{array}$ & $\begin{array}{l}342 \mathrm{~b} \\
(67.7)\end{array}$ & $\begin{array}{l}163 \mathrm{~b} \\
(32.3)\end{array}$ & $505(100.0)$ & & \\
\hline $\begin{array}{l}\text { Sleep Factors } \\
(\mathrm{Sf})\end{array}$ & $\begin{array}{l}306 b \\
(60.6)\end{array}$ & $\begin{array}{l}199 \mathrm{~b} \\
(39.4)\end{array}$ & $505(100.0)$ & & \\
\hline
\end{tabular}

Each letter $(a, b)$ represents a subset of the framing messages selection. Statistical differences were observed in the selection ratio of the framing messages between two groups when the revised test level was $\alpha=0.0083$. ${ }^{* *} p<0.001$ (statistically significant).

Table 4. Binary logistic regression for goal framing.

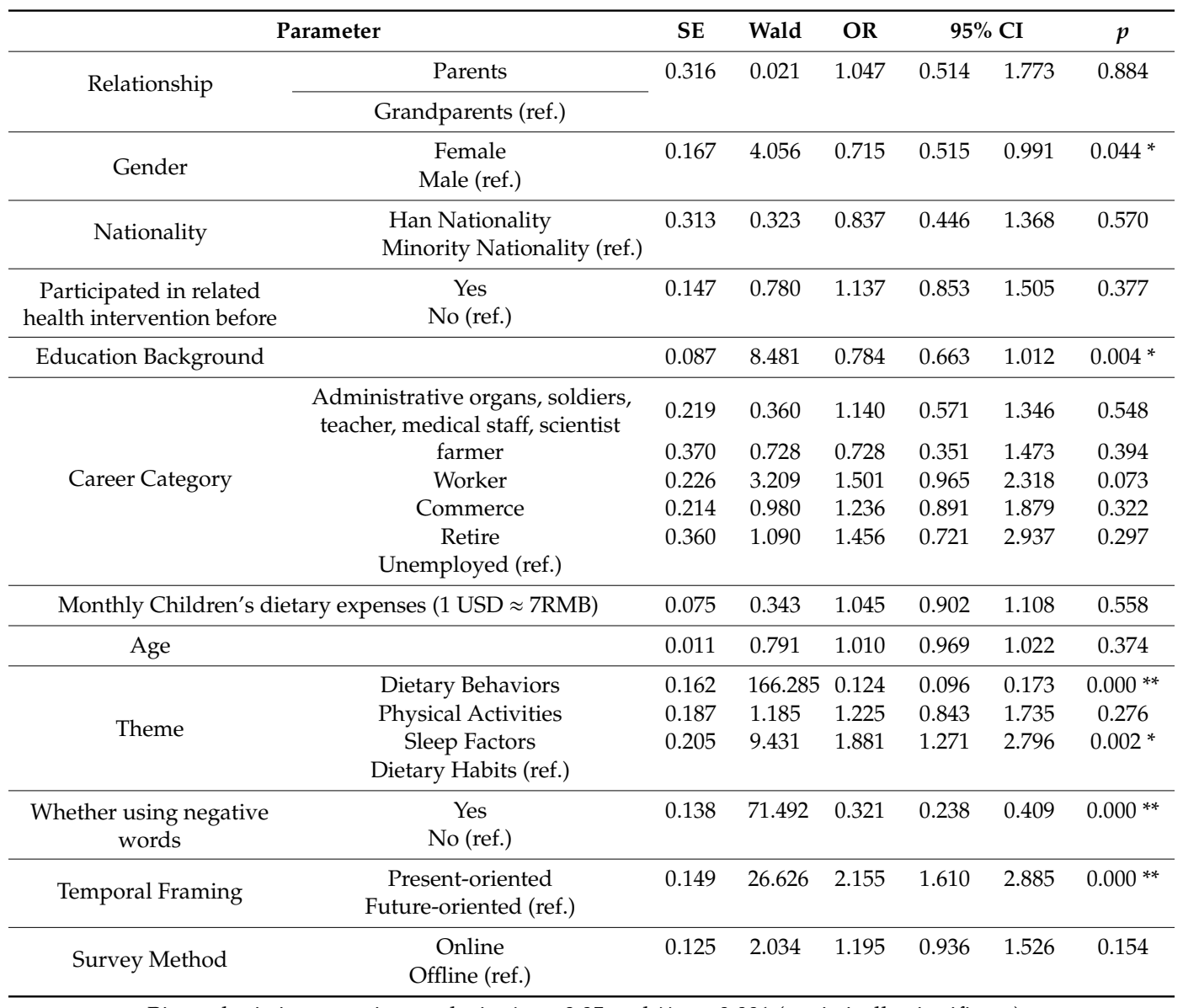

Binary logistic regression analysis. ${ }^{*} p<0.05$ and ${ }^{* *} p<0.001$ (statistically significant). 
As shown in Table 5, in the temporal framing model, whether one participated in a health related intervention before, career category, theme, and goal framing were statistically significant $(p<$ 0.05). Caregivers with the experience of a health related intervention were more willing to accept the future-oriented message. Compared with the unemployed caregivers, peasant caregivers were more willing to accept a present-oriented message. Compared with the Dh theme, caregivers were more willing to accept a future-oriented message in the $\mathrm{Pa}$, Sf theme. The combination of the message and gain-framed frame made caregivers more willing to accept a present-oriented message.

Table 5. Binary logistic regression for temporal framing.

\begin{tabular}{|c|c|c|c|c|c|c|c|}
\hline \multicolumn{2}{|c|}{ Parameter } & \multirow{2}{*}{$\frac{\text { SE }}{0.281}$} & \multirow{2}{*}{$\begin{array}{l}\text { Wald } \\
0.027\end{array}$} & \multirow{2}{*}{$\begin{array}{c}\text { OR } \\
1.047\end{array}$} & \multicolumn{2}{|c|}{$95 \% \mathrm{CI}$} & \multirow{2}{*}{$\frac{p}{0.870}$} \\
\hline \multirow{2}{*}{ Relationship } & Parents & & & & 0.603 & 1.757 & \\
\hline & Grandparents (ref.) & & & & & & \\
\hline Gender & $\begin{array}{c}\text { Female } \\
\text { Male (ref.) }\end{array}$ & 0.144 & 0.833 & 1.140 & 0.860 & 1.512 & 0.361 \\
\hline Nationality & $\begin{array}{l}\text { Han Nationality } \\
\text { Minority Nationality (ref.) }\end{array}$ & 0.285 & 0.037 & 0.946 & 0.604 & 1.848 & 0.847 \\
\hline $\begin{array}{l}\text { Participated in health related } \\
\text { intervention before }\end{array}$ & $\begin{array}{c}\text { Yes } \\
\text { No (ref.) }\end{array}$ & 0.128 & 8.409 & 0.690 & 0.545 & 0.903 & $0.004^{*}$ \\
\hline Education Background & & 0.078 & 0.292 & 0.958 & 0.822 & 1.121 & 0.598 \\
\hline \multirow{5}{*}{ Career Category } & $\begin{array}{l}\text { Administrative organs, soldiers, } \\
\text { teacher, medical staff, scientist }\end{array}$ & 0.205 & 1.420 & 0.783 & 0.525 & 1.174 & 0.233 \\
\hline & farmer & 0.441 & 4.697 & 2.604 & 1.096 & 6.162 & 0.030 * \\
\hline & Worker & 0.203 & 1.395 & 0.787 & 0.528 & 1.174 & 0.238 \\
\hline & Commerce & 0.202 & 0.434 & 0.876 & 0.587 & 1.301 & 0.510 \\
\hline & $\begin{array}{c}\text { Retire } \\
\text { Unemployed (ref) }\end{array}$ & 0.305 & 0.333 & 1.192 & 0.649 & 2.172 & 0.564 \\
\hline \multicolumn{2}{|c|}{ Monthly children's dietary expenses (1USD $\approx 7 R M B)$} & 0.067 & 1.082 & 0.932 & 0.814 & 1.061 & 0.298 \\
\hline \multicolumn{2}{|l|}{ Age } & 0.010 & 2.780 & 0.983 & 0.962 & 1.003 & 0.095 \\
\hline \multirow{4}{*}{ Theme } & Dietary Behaviors & 0.224 & 1.090 & 1.264 & 0.826 & 1.951 & 0.296 \\
\hline & Physical Activities & 0.172 & 61.351 & 0.259 & 0.186 & 0.368 & $0.000 * *$ \\
\hline & Sleep Factors & 0.171 & 99.623 & 0.182 & 0.131 & 0.255 & $0.000^{* *}$ \\
\hline & Dietary Habits (ref.) & & & & & & \\
\hline Whether using negative words & $\begin{array}{c}\text { Yes } \\
\text { No (ref.) }\end{array}$ & 0.188 & 2.474 & 1.344 & 0.930 & 1.944 & 0.116 \\
\hline Goal Framing & $\begin{array}{c}\text { Gain-framed } \\
\text { Loss-framed (ref.) }\end{array}$ & 0.187 & 26.058 & 2.602 & 1.802 & 3.756 & $0.000 * *$ \\
\hline Survey Method & $\begin{array}{c}\text { Online } \\
\text { Offline (ref.) }\end{array}$ & 0.113 & 0.501 & 1.083 & 0.868 & 1.353 & 0.479 \\
\hline
\end{tabular}

Binary logistic regression analysis. ${ }^{*} p<0.05$ and ${ }^{* *} p<0.001$ (statistically significant).

\section{Discussion}

Few previous studies have explored message framing for caregivers of preschool children to address simple obesity. In the study, we found that the GP message showed salience for acceptance in terms of dietary habits $(385,76.2 \%)$, physical activities, $(304,60.2 \%)$, and sleep factors $(276,54.7 \%)$. In terms of dietary behavior, 253 (50.1\%) caregivers found the LP message acceptable. We synthesized the four theme messages and found that the gain-framed message was more acceptable than the loss-framed message (gain versus loss $=1503: 517$ ); the present-oriented message was more acceptable than the future-oriented message (present versus future $=1530: 490$ ). Then, we discussed some factors that would affect the framing effects through statistical analysis.

Firstly, using negative words in the message may affect the goal-framing effects. The result in Table 2 showed that GP message was most acceptable by caregivers except in Db. The results of further analysis are shown in Table 3; in terms of $\mathrm{Dh}, \mathrm{Pa}$, and Sf, the gain-framed message was more acceptable, whereas for $\mathrm{Db}$, the loss-framed message was more acceptable $(p<0.05)$. As shown in Table 4 , the existence of negative words and $\mathrm{Db}$ theme made caregivers more willing to accept the 
loss-framed message than the gain-framed message $(p<0.05)$. In order to explore the reason, we compared the characteristics of sentences under each theme. The framing messages were commonly designed as sentences, consisting of presuppositions of conditional propositions (antecedent framing) and consequent propositions (consequent framing) [25,44]. The affirmative sentences were used as conditional sentences, and the profit phenomenon was described as a resulting sentence, which formed a gain-framed message. By contrast, the negative sentences were used as conditional sentences, and the loss phenomenon was described as consequential sentences, thereby forming a loss-framed message. In $\mathrm{Dh}, \mathrm{Pa}$, and Sf theme, we followed these rules. But watching TV is a risk factor for obesity in dietary behavior $(\mathrm{Db})$; we used negative sentences as conditional sentences to form a gain-framed message (matching a profitable result) and affirmative sentences as conditional sentences to form a loss-framed message (matching a loss result). The comparison of text materials is shown in Appendix A. The results showed that the different choices caregivers made in $\mathrm{Db}$ theme are probably related to the collocation conflict between negative words and frames. The inclusion of negative words in sentences slows down message processing and predisposes receivers to errors $[45,46]$. Meanwhile, using negative and affirmative sentences may lead to different psychological processes [47]. In summary, we suggest that further study on the relationship between negative words use and framing effects could help us better understand framing effects.

Then, with the increase of temporal framing in a message, the effect of temporal framing might become weaker. Traditional psychological studies have long noted the human tendency to discount temporally distant consequences [48]. Temporal-discounting research also shows that present-oriented consequences have more psychological value than future-oriented consequences [49]. Our overall research results were consistent with this finding. However, the influence of the temporal-framing effects on caregivers was different in four different thematic messages (Tables 3 and 4). It is worth noting that when filling in the questionnaire, caregivers were required to read framing messages in existing order and choose the most acceptable message in one theme according to the order in which they appeared. The order of the theme was Dh (number 1), Db (number 2), Pa (number 3), and Sf (number 4). The results show that there was a trend of increasing the proportion of caregivers who thought the future-oriented message was more acceptable, with the increase of the serial number corresponding to the theme. With the increase of the temporal framing of a message, the proportion of present-oriented and future-oriented message selection approaches 1. Construal level theory is used to explain the temporal framing effects [30]. People tend to underestimate the value and importance of future events and outcomes because a future-oriented message is related to abstract psychological representations [50,51]. Therefore, a future-oriented message creates a low perceived risk. But our results suggested that increasing the number of framing messages may enable individuals to examine and assess the differences between future and present-oriented messages, and this tendency to underestimate the future is ultimately reduced. We thought this was a good way to study temporal framing effects.

At last, many factors might affect the frame effects. First, gender is an important factor influencing the goal framing effects. Huang et al. [37] found that women were more likely to be affected by the loss-framed messages when it came to life and death. Our results also show that the female group is more reluctant to accept the gain-framed message, which may be due to the pressure and responsibility of raising children [52]. Second, the influence of knowledge level on framing effects is not conclusive. Our result was similar to the result of Haider et al [35]. That is to say, people with low education were more likely to choose the gain-framed message under the influence of goal framing effects. Third, is whether participation in a relevant health intervention is the embodiment of personal involvement [53]. Many kinds of literature have confirmed that participants with higher personal involvement are more likely to be influenced by the goal-framing message [25]. However, the interaction between personal involvement and temporal framing shows a lack of detailed research. Time preference changed dynamically with the change of human sensitivity to duration [54]. The result of our study may suggest that getting the relevant knowledge in advance might reduce the sensitivity to time, thereby making caregivers more willing to accept the future-oriented message. It would be 
a good idea to research temporal framing effects. Fourth, farmers tend to maintain more traditional health attitudes and eating habits. Our result suggested that the present-oriented message might be applied in health education in rural areas. These results showed that when publicizing the message of children's obesity in a specific population with caregivers, the more suitable framing message can be selected according to the characteristics of the caregivers.

This study has several limitations. First, we adopted a convenient sampling method in the experimental design to ensure that the subjects included in the study were willing to read our information materials carefully. However, we increased the contingency and reduced the typicality of the samples. Second, because our survey was conducted in urban public kindergartens, the number of individuals with different demographic characteristics varied. In particular, there was a lack of rural participants. At the same time, there were not enough grandparents, males, and individuals with low educational backgrounds. Therefore, the sample of these groups was less representative of choosing the framing messages. It is worth noting that there were differences in demographic characteristics between the online and offline groups. Although the survey method had no statistical impact on the selection of framing messages, it still suggested that the online questionnaire has limitations on the selection of the population. Third, in the framing messages design, the use of negative expression under the dietary behavior theme was different from that under other themes, and only this group used a negative expression in the gain-framed message. We did not have a strict control experiment on the use of negative words. Fourth, due to the lacking literature regarding farmers and framing effects, our discussion on farmers has a lack of scientific basis, which reduces its credibility. Finally, the study relied on self-reporting, which can introduce bias because of dishonesty, over-reporting, under-reporting, and measurement flaws. These limitations could open interesting avenues for further research. Despite these limitations, this study provided insight into the use of framing message in the context of preschool children's obesity health education among children's caregivers in China.

\section{Conclusions}

In this cross-sectional study among 505 caregivers of preschool children in urban kindergartens, the gain-framed message and present-oriented message were most salient for stimulating the majority of caregivers to accept health messages. This research further supports the view that in the use of framing effects, the goal framing and the temporal framing can be used interactively. However, we should strictly control the sentence structure when compiling a health framing message. We speculate that the use of negative words in the message may affect the goal framing effects, and the quantity of messages may affect the temporal framing effects. However, the specific impact process should be explored in future studies. Other factors, such as gender, education background, participation in a health intervention, and career category, which might affect the framing effects, can help us release targeted health messages for specific groups of people to improve their acceptance of the message.

Author Contributions: X.H., Y.Z., A.S.A., Q.R., and L.B. designed the experiments. X.H., Y.Z., Q.R., and L.B., performed the experiments. Y.X. helped perform the experiments. Q.R. analyzed the data. Y.L. helped analyze the data. X.H., Y.Z., I.B., and Y.L. helped draft the manuscript. All authors read and approved the final manuscript.

Funding: This research was funded by the College of Medical Informatics, Chongqing Medical University, China, Student Research and Innovation Experiment Project (grant number 2019C002); Chongqing Medical University, China, the Special Research Project of Philosophy and Social Science (grant number 201712); the Intelligent Health Knowledge Discovery and Information Service in Chongqing Medical University (ZHYX2019006); and the Chinese Scholarship Council of the Ministry of Education (grant number 201808505165).

Acknowledgments: Kindergarten of Chongqing Municipal Government (2019-3-20), Haibeining kindergarten (2019-4-8), Home-Textile City Dadi kindergarten (2019-4-17), Aidi-Mengshi kindergarten (2019-4-25), Xingxing kindergarten (2019-5-15), Qingzhou kindergarten (2019-5-28), Yuanjiagang kindergarten (2019-6-10), Yinghua Beibei kindergarten (2019-6-16). We would like to thank all kindergartens that helped coordinate the survey and the caregivers who participated in the study.

Conflicts of Interest: The authors declare no conflicts of interest. The funders had no role in the design of the study; in the collection, analyses, or interpretation of data; in the writing of the manuscript, or in the decision to publish the results. 


\section{Appendix A}

Table A1. Message framing materials used in the survey.

\begin{tabular}{|c|c|c|}
\hline Theme & Present-Oriented & Future-Oriented \\
\hline \multicolumn{3}{|c|}{ Gain-framed } \\
\hline Dietary habits & $\begin{array}{c}\text { If we encourage children to eat more grain and vegetable, they will get } \\
\text { adequate dietary fiber. }\end{array}$ & $\begin{array}{l}\text { If we encourage children to eat more grain and vegetable, the risk of } \\
\text { diabetes will be decreased in adulthood. }\end{array}$ \\
\hline Dietary behaviors & $\begin{array}{l}\text { If we guide children to eat food with not watching } \mathrm{TV} \text {, it can conducive to } \\
\text { digestion and absorption. }\end{array}$ & $\begin{array}{l}\text { If we guide children to eat food with not watching TV, the risk of gastric } \\
\text { diseases will be decreased in adulthood. }\end{array}$ \\
\hline Physical activities & $\begin{array}{l}\text { If we encourage children to exercise at least } 1 \text { hour per day, children's motor } \\
\text { function will be enhanced. }\end{array}$ & $\begin{array}{l}\text { If we encourage children to exercise at least } 1 \text { hour per day, the risk of } \\
\text { cardiovascular disease will be decreased in adulthood. }\end{array}$ \\
\hline Sleep factors & $\begin{array}{l}\text { If we make sure children keep sleeping } 10 \text { to } 13 \text { hours per day, it will benefit } \\
\text { for their memory consolidation and energy recovery. }\end{array}$ & $\begin{array}{l}\text { If we make sure children keep sleeping } 10 \text { to } 13 \text { hours per day, it will be } \\
\text { benefit for children nervous system and brains development in future. }\end{array}$ \\
\hline \multicolumn{3}{|c|}{ Loss-framed } \\
\hline Dietary habits & $\begin{array}{l}\text { If we do not encourage children to eat more grain and vegetable, they will not } \\
\text { get enough dietary fiber. }\end{array}$ & $\begin{array}{l}\text { If we do not encourage children to eat more grain and vegetable, the risk } \\
\text { of diabetes will be increased in adulthood. }\end{array}$ \\
\hline Dietary behaviors & $\begin{array}{l}\text { If we allow children watching TV while eating food, they may have } \\
\text { indigestion. }\end{array}$ & $\begin{array}{l}\text { If we allow children watching TV while eating food, their gastric } \\
\text { function will be more likely to be bad in adulthood. }\end{array}$ \\
\hline Physical activities & $\begin{array}{l}\text { If we do not encourage children to exercise at least } 1 \text { hour per day, children's } \\
\text { motor function will be weakened. }\end{array}$ & $\begin{array}{l}\text { If we do not encourage children to exercise at least } 1 \text { hour per day, the } \\
\text { risk of cardiovascular disease will be increased in adulthood. }\end{array}$ \\
\hline Sleep factors & $\begin{array}{l}\text { If we do not make sure children keep sleeping } 10 \text { to } 13 \text { hours per day, the } \\
\text { feeling of fatigue in children will be increased. }\end{array}$ & $\begin{array}{l}\text { If we do not make sure children keep sleeping } 10 \text { to } 13 \text { hours per day, it } \\
\text { will be averse to their nervous system and brains development in future. }\end{array}$ \\
\hline
\end{tabular}




\section{Appendix B}

Table A2. Questionnaire items of caregivers' acceptance choices to framing messages. (Take Dietary habits as an example).

\begin{tabular}{c}
$\frac{\text { Dietary Habits }}{\text { We May Have Many Different Strategies in Children's Food Choices. The Most Acceptable Sentence You will Choice is: }}$ Use $(\sqrt{ })$ to Represent Your Most Acceptable Sentence \\
\hline If we encourage children to eat more grain and vegetable, they will get adequate dietary fiber. \\
\hline If we encourage children to eat more grain and vegetable, the risk of diabetes will be decreased in adulthood. \\
\hline If we do not encourage children to eat more grain and vegetable, they will not get enough dietary fiber. \\
\hline
\end{tabular}




\section{References}

1. World Health Organization Frequently asked questions: Childhood obesity. Available online: https: //www.who.int/end-childhood-obesity/faq/en/ (accessed on 11 January 2020).

2. Looi, L.-M.; Prentice, A.; Griffin, G.; Jebb, S.; Khor, G.L.; Poston, L.; Veerakumarasivam, A.; Wareham, N.; Lee, Y.Y.; Zain, A. Addressing the Global Health Challenge of Obesity in Malaysia Workshop Report; The Academy of Medical Sciences: Kuala Lumpur, Malaysia, 2018.

3. World Health Organization 10 facts on obesity. Available online: https://www.who.int/features/factfiles/ obesity/zh/ (accessed on 1 June 2019).

4. Poskitt, E.M.E. Childhood obesity in low- and middle-income countries. Paediatr. Int. Child Health 2014, 34, 239-249. [CrossRef] [PubMed]

5. Geserick, M.; Lipek, T.; Spielau, U.; Pfäffle, R.; Kiess, W.; Körner, A.; Vogel, M.; Gausche, R.; Keller, E. Acceleration of BMI in early childhood and risk of sustained obesity. N. Engl. J. Med. 2018, 379, 1303-1312. [CrossRef] [PubMed]

6. $\quad$ Liang, Y.; Hou, D.; Zhao, X.; Wang, L.; Hu, Y.; Liu, J.; Cheng, H.; Yang, P.; Shan, X.; Yan, Y.; et al. Childhood obesity affects adult metabolic syndrome and diabetes. Endocrine 2015, 50, 87-92. [CrossRef] [PubMed]

7. Pollock, B.D.; Chen, W.; Harville, E.W.; Shu, T.; Fonseca, V.; Mauvais-Jarvis, F.; Kelly, T.N.; Bazzano, L.A. Differential sex effects of systolic blood pressure and LDL-C on Type 2 diabetes: Life-course data from the Bogalusa Heart Study. J. Diabetes 2017, 10, 449-457. [CrossRef] [PubMed]

8. Zapletal, A.; Chalupová, J. Forced expiratory parameters in healthy preschool children (3-6 years of age). Pediatr. Pulmonol. 2003, 35, 200-207. [CrossRef] [PubMed]

9. Yun, M.W.; Abdullah, N.L.; Idrus, R.; Keikhosrokiani, P. Lifestyle disease prevention: Health literacy, health attitude and mHealth. 2017 Int. Conf. Res. Innov. Inf. Syst. ICRIIS 2017. [CrossRef]

10. Sandvik, P.; Ek, A.; Somaraki, M.; Hammar, U.; Eli, K.; Nowicka, P. Picky eating in Swedish preschoolers of different weight status: Application of two new screening cut-offs. Int. J. Behav. Nutr. Phys. Act. 2018, 15, 1-12. [CrossRef]

11. Reilly, J.J. Physical activity, sedentary behaviour and energy balance in the preschool child: Opportunities for early obesity prevention. Proc. Nutr. Soc. 2008, 67, 317-325. [CrossRef]

12. Chen, J.L.; Esquivel, J.H.; Guo, J.; Chesla, C.A.; Tang, S. Risk factors for obesity in preschool-aged children in China. Int. Nurs. Rev. 2018, 65, 217-224. [CrossRef]

13. Chen, X.; Yang, J.; Peek-Asa, C.; McGehee, D.V.; Li, L. Parents' knowledge, attitude, and use of child restraints, Shantou, China. Am. J. Prev. Med. 2014, 46, 85-88. [CrossRef]

14. He, L.; Zhai, Y.; Engelgau, M.; Li, W.; Qian, H.; Si, X.; Gao, X.; Sereny, M.; Liang, J.; Zhu, X.; et al. Association of children's eating behaviors with parental education, and teachers' health awareness, attitudes and behaviors: A national school-based survey in China. Eur. J. Public Health 2014, 24, 880-887. [CrossRef] [PubMed]

15. Liu, S.; Zhou, H.; Ma, J.; Wang, C.; Chen, Z.; Chen, S.; Yang, Y.; Liu, X.; Peng, J.; Duan, L.; et al. Knowledge, attitudes, and behaviors related to child safety restraint in citizens of Shenzhen Municipality, China, and the associations between these factors. Traffic Inj. Prev. 2018, 19, 42-48. [CrossRef] [PubMed]

16. Klein, D.; De Toia, D.; Weber, S.; Wessely, N.; Koch, B.; Dordel, S.; Sreeram, N.; Tokarski, W.; Strüder, H.; Graf, C. Effects of a low threshold health promotion intervention on the BMI in pre-school children under consideration of parental participation. e-SPEN 2010, 5, e125-e131. [CrossRef]

17. Ling, J.; Robbins, L.B.; Wen, F. Interventions to prevent and manage overweight or obesity in preschool children: A systematic review. Int. J. Nurs. Stud. 2016, 53, 270-289. [CrossRef] [PubMed]

18. Ownby, R.L.; Acevedo, A.; Waldrop-Valverde, D.; Jacobs, R.J.; Caballero, J. Abilities, skills and knowledge in measures of health literacy. Patient Educ. Couns. 2014, 95, 211-217. [CrossRef] [PubMed]

19. Meppelink, C.S.; van Weert, J.C.; Haven, C.J.; Smit, E.G. The Effectiveness of Health Animations in Audiences With Different Health Literacy Levels: An Experimental Study. J. Med. Internet Res. 2015, 17, e11. [CrossRef]

20. Meppelink, C.S.; Smit, E.G.; Buurman, B.M.; van Weert, J.C.M. Should We Be Afraid of Simple Messages? The Effects of Text Difficulty and Illustrations in People With Low or High Health Literacy. Health Commun. 2015, 30, 1181-1189. [CrossRef] [PubMed] 
21. Muller, I.; Rowsell, A.; Stuart, B.; Hayter, V.; Little, P.; Ganahl, K.; Müller, G.; Doyle, G.; Chang, P.; Lyles, C.R.; et al. Effects on Engagement and Health Literacy Outcomes of Web-Based Materials Promoting Physical Activity in People With Diabetes: An International Randomized Trial. J. Med. Internet. Res. 2017, 19 , e21. [CrossRef]

22. Kahneman, D.; Tversky, A. The Framing of Decisions and the Psychology of Choice. Science 1981, 211, 453-458.

23. Meyerowitz, B.E.; Chaiken, S. The Effect of Message Framing on Breast Self-Examination Attitudes, Intentions, and Behavior. J. Pers. Soc. Psychol. 1987, 52, 500-510. [CrossRef]

24. Gallagher, K.M.; Updegraff, J.A. Health Message Framing Effects on Attitudes, Intentions, and Behavior: A Meta-analytic Review. Ann. Behav. Med. 2011, 43, 101-116. [CrossRef] [PubMed]

25. Bai, L.; Cai, Z.; Lv, Y.; Wu, T.; Sharma, M.; Shi, Z.; Hou, X.; Zhao, Y. Personal involvement moderates message framing effects on food safety education among medical university students in Chongqing, China. Int. J. Environ. Res. Public Health 2018, 15, 1-15. [CrossRef]

26. Myers, R.E. Promoting healthy behaviors: How do we get the message across? Int. J. Nurs. Stud. 2010, 47, 500-512. [CrossRef] [PubMed]

27. Kahneman, D.; Tversky, A. Prospect Theory: An Analysis of Decision under Risk. Econometrica 1979, 47, 263-291. [CrossRef]

28. Alexander, R.; Peter, S. Shaping perceptions to motivate healthy behavior: The role of message framing. Psychol. Bull. 1997, 121, 3-19.

29. Gerend, M.A.; Shepherd, J.E. Using Message Framing to Promote Acceptance of the Human Papillomavirus Vaccine. Heal. Psychol. 2007, 26, 745-752. [CrossRef]

30. Trope, Y.; Liberman, N. Temporal construal and time-dependent changes in preference. J. Personal. Soc. Psychol. 2000, 79, 876-889. [CrossRef]

31. Gerend, M.A.; Cullen, M. Effects of message framing and temporal context on college student drinking behavior. J. Exp. Soc. Psychol. 2008, 44, 1167-1173. [CrossRef]

32. De Bruijn, G.J.; Spaans, P.; Jansen, B.; Van't Riet, J. Testing the effects of a message framing intervention on intentions towards hearing loss prevention in adolescents. Health Educ. Res. 2016, 31, 161-170. [CrossRef]

33. Churchill, S.; Pavey, L.; Jessop, D.; Sparks, P. Reducing alcohol consumption: the influence of message frame, temporal context and autonomy. Eur. Heal. Psychol. 2015, 17, 763.

34. Van 't Riet, J.; Cox, A.D.; Cox, D.; Zimet, G.D.; De Bruijn, G.J.; Van den Putte, B.; De Vries, H.; Werrij, M.Q.; Ruiter, R.A.C. Does perceived risk influence the effects of message framing? Revisiting the link between prospect theory and message framing. Health Psychol. Rev. 2016, 10, 447-459. [CrossRef] [PubMed]

35. Haider-Markel, D.P.; Joslyn, M.R. Gun Policy, Opinion, Tragedy, and Blame Attribution: The Conditional Influence of Issue Frames. J. Polit. 2001, 63, 520-543. [CrossRef]

36. Block, L.G.; Williams, P. Undoing The Effects Of Seizing And Freezing: Decreasing Defensive Processing Of Personally Relevant Messages. J. Appl. Soc. Psychol. 2000, 32, 803-830. [CrossRef]

37. Huang, Y.; Wang, L. Sex differences in framing effects across task domain. Pers. Individ. Dif. 2010, 48, 649-653. [CrossRef]

38. Jarrin, D.C.; McGrath, J.J.D.C.L. Beyond sleep duration: distinct sleep dimensions are associated with obesity in children and adolescents. Int. J. Obes (Lond). 2013, 37, 552-558. [CrossRef]

39. Hruby, A.; Manson, J.A.E.; Qi, L.; Malik, V.S.; Rimm, E.B.; Sun, Q.; Willett, W.C.; Hu, F.B. Determinants and consequences of obesity. Am. J. Public Health 2016, 106, 1656-1662. [CrossRef]

40. World Health Organization Promoting fruit and vegetable consumption around the world. Available online: https://www.who.int/dietphysicalactivity/fruit/en/ (accessed on 11 January 2020).

41. Megan Brooks New AASM Guideline on Optimal Sleep for Children. Available online: https://www. medscape.com/viewarticle/864846 (accessed on 11 January 2020).

42. Styne, D.M.; Arslanian, S.A.; Connor, E.L.; Farooqi, I.S.; Murad, M.H.; Silverstein, J.H.; Yanovski, J.A. Pediatric obesity-assessment, treatment, and prevention: An endocrine society clinical practice guideline. J. Clin. Endocrinol. Metab. 2017, 102, 709-757. [CrossRef]

43. Wang, S.; Lay, S.; Yu, H.; Shen, S. Dietary Guidelines for Chinese Residents (2016): comments and comparisons. J. Zhejiang Univ. Sci. B 2016, 17, 649-656. [CrossRef] 
44. Satia, J.A.; Barlow, J.; Armstrong-brown, J.; Watters, J.L. A qualitative study to explore Prospect theory and message framing and diet and cancer prevention-related issues among African American adolescents. Cancer Nurs. 2011, 33, 102-109. [CrossRef]

45. Clark, H.H.; Chase, W.G. On the process of comparing sentences against pictures. Cogn. Psychol. 1972, 3, 472-517. [CrossRef]

46. Deutsch, R.; Kordts-Freudinger, R.; Gawronski, B.; Strack, F. Fast and fragile: A new look at the automaticity of negation processing. Exp. Psychol. 2009, 56, 434-446. [CrossRef] [PubMed]

47. Holleman, B.C. The meanings of 'yes' and 'no'. An explanation for the forbid/allow asymmetry. Qual. Quant. 2006, 40, 1-38. [CrossRef]

48. Critchfield, T.S.; Kollins, S.H. Temporal discounting: basic research and the analysis of socially important behavior. J. Appl. Behav. Anal. 2001, 34, 101-122. [CrossRef]

49. Liberman, N.; Trope, Y. The psychology of transcending the here and now. Science 2008, 322, 1201-1205. [CrossRef] [PubMed]

50. Liberman, N.; Trope, Y. The Role of Feasibility and Desirability Considerations in Near and Distant Future Decisions: A Test of Temporal Construal Theory. J. Personal. Soc. Psychol. 1998, 75, 5-18. [CrossRef]

51. Kim, J.; Nan, X. Temporal framing effects differ for narrative versus non-narrative messages: The case of promoting HPV vaccination. Communic. Res. 2019, 46, 401-417. [CrossRef]

52. Stern, M.J.; Cotten, S.R.; Drentea, P. The Separate Spheres of Online Health: Gender, Parenting, and Online Health Information Searching in the Information Age. J. Fam. Issues 2011, 33, 1324-1350. [CrossRef]

53. Chen, S.; Shechter, D.; Chaiken, S. Getting at the Truth or Getting Along: Accuracy- Versus Impression-Motivated Heuristic and Systematic Processing. J. Pers. Soc. Psychol. 1996, 71, 262-275. [CrossRef]

54. Zauberman, G. The Intertemporal Dynamics of Consumer Lock-in. J. Consum. Res. 2005, 30, 405-419. [CrossRef]

(C) 2020 by the authors. Licensee MDPI, Basel, Switzerland. This article is an open access article distributed under the terms and conditions of the Creative Commons Attribution (CC BY) license (http://creativecommons.org/licenses/by/4.0/). 